\title{
Views of Instructors Towards Students Learning English Public Speaking at a Malaysian University
}

\section{Ahmad Taufik Hidayah b. Abdullah and Mohd Nazri b. Latiff Azmi}

Universiti Sultan Zainal Abidin (UniSZA), Terengganu, Malaysia

\section{Abstract}

Public speaking was one of the most feared situations faced by many people, including public speaking in the English language. Speaking English in front of the public was really a daunting task for many people, including students of universities. This study addressed issues related to English public speaking at the university from the views of instructors who taught the English public speaking course. Some topics discussed were the common weaknesses of university students in delivering English public speaking, the causes of the weaknesses and some recommendations for students to improve their English public speaking. This was a qualitative research design where eleven

Corresponding Author: Ahmad Taufik Hidayah b.

Abdullah

taufikhidayah@unisza.edu.my

Received: 1 July 2019

Accepted: 18 July 2019

Published: 31 July 2019

Publishing services provided by Knowledge $E$

(c) Ahmad Taufik Hidayah b. Abdullah and Mohd Nazri b. Latiff Azmi et al. This article is distributed under the terms of the Creative Commons

Attribution License, which permits unrestricted use and redistribution provided that the original author and source are credited.

Selection and Peer-review unde the responsibility of the AICLL 2019 Conference Committee.

\section{G OPEN ACCESS} instructors teaching English public speaking were interviewed and the gathered data were analyzed using thematic analysis and presented using Atlas. ti version 7. One of the theories employed in the study was the Uncertainty Reduction Theory that made their anxiety level increase. The study revealed that some common weaknesses of students were lack of confidence, limited vocabulary and grammar. Some contributing causes of the weaknesses were lack of reading, lack of ideas, and lack of self-esteem. Some recommendations were then forwarded to solve the problems such as giving the motivation to the students to speak, read and think in the English language and make a lot of practices.

Keywords: English public speaking, university, students, Instructors, UniSZA, Malaysia

\section{Introduction}

In the context of tertiary education in Malaysia, English is taught as one of the compulsory subjects to take and pass. The importance of mastering good English has been emphasised by the government by introducing more and more improvements in the syllabus of the teaching and learning of English starting from the primary school up to university. This effort is aimed at improving the quality of the teaching of English thus enabling to produce students or graduates who are competent and proficient in the English language. 
There are some common courses offered at the university level in Malaysia as far as the English language is concerned. The English language courses have been designed to meet the need of the students during their studies. A course like Academic Writing will help students in their studies to enable them to write in proper English writing. Some other English courses will equip graduates with practical knowledge in English once they complete their studies. Two examples of this kind of course are: English for Occupational Purposes or Business English, and Public Speaking. The importance of public speaking is in dire need especially in Business English classes to enhance good communication and presentation skills.

Public speaking in English as one of the offered subjects or might be a part or component of an English course at the university will help students in the preparation and presentation of a decently accepted English public speaking. This course will equip students with the necessary knowledge, skills and above all exposures. Some factors do influence and affect the students with regard to their achievement in English public speaking. Characters of the instructors, in terms of personality or teaching styles, coupled with their method in delivery or teaching will be some important and deciding factors in the success of the students in English public speaking.

\section{Literature Review}

Unlike daily conversation, an oral presentation or public speaking needs more detailed and complex preparation since it has to adhere to some characteristics and conditions in order to meet its objectives. Three elements or characteristics of a good oral presentation are stated by Choo Wan Yat, Yee Sook Fen \& Yeoh Wei Tzee (2006) as follows:

Firstly, an oral presentation is highly structured. It needs detailed planning and preparation. The management of time is very important since a speaker will only speak in a specified time. A well-timed and planned presentation is needed to meet the objective of the presentation. The audience might not pose questions during the presentation but they can be raised after the presentation. In that case, a presenter needs to anticipate any possible questions that are posted.

Secondly, an oral presentation uses a more formal language. The choice of words or phrases in the conveyed speech is very crucial. A speaker cannot use a language deemed too strong or too colloquial since it can cause a negative reaction from the audience. A speaker is also expected not to use some slangs, jargon as well as bad grammar since it can enable the audience to give a bad impression on the speaker. 
Thirdly, a good oral presentation needs a certain method of delivery. Unlike in daily conversion where people use a lot of interjections such as "you know" or "you see" and adopt a casual posture and use pauses and fillers such as "err" or "hmm", in an oral presentation a speaker needs to avoid these. Being an effective speaker one must make sure that he or she has a good projection of voice as well as a good posture in front of the audience.

The English language has become an international medium of communication among the people on earth. The mastery of good English is deemed as having an edge and can bring a lot of advantages in many ways. We cannot imagine how two people from two countries whose mother tongues are not English would contact and communicate with each other. A native person from Africa and a Malaysian would only be able to communicate if they had a shared language that can be understood by both sides. This international language is not only used for communicational purposes but also in the fields of technology, commerce, education and many other aspects of life (Ahmad Taufik Hidayah, 2007).

From a communicative, pragmatic view of the language classroom, listening and speaking skills are closely intertwined. More often than not, ESL curricula that treat oral communication skills will simply be labeled as "Listening/Speaking" courses (Brown, 2007). There are some issues related to oral communication skills in pedagogical research such as conversational discourse, teaching pronunciation, accuracy and fluency, affective factors, interaction effect, questions about intelligibility, the growth of spoken corpora and genres of spoken language (Brown, 2007).

There are some principles for teaching speaking skills in the classroom (Brown, 2007). Firstly, focus on both fluency and accuracy, depending on the objectives. Secondly, provide intrinsically motivating techniques. By giving ample techniques will make the students motivated in their speaking. And then, try encouraging the use of authentic language in a meaningful context. The next step is, to provide appropriate feedback and correction when the speaking activity is done.

Another approach in teaching speaking in English is proposed by Chitravelu, et.al (2005) as outlined in her book, ELT Methodology: Principles and Practice, where the process of teaching speaking in English must consider the following factors. First, the teacher or instructor should take account of the student as a person. The teacher has to be sensitive, sympathetic and encouraging. Besides, the selection of materials should be motivating and within the ability of the students. Secondly, the teacher must help reduce anxiety of the student by moving from easy to more difficult lessons. 
Public speaking, as one of the course contents in English language subject taught at the university, has been the subject that many students perceive as difficult and quite challenging for them. The researcher involves discussions on English public speaking from the perspective of students themselves; characteristics of instructors or lecturers teaching the subjects as well as the methods used in teaching English speaking, including English public speaking.

Roya and Saeideh (2016) investigated characteristics of an effective English language teacher (EELT) as perceived by learners of English. It aims at characterizing and investigating qualities of an effective English language teacher perceived by Iranian English language learners. The findings showed that what the students perceived as characteristics of effective English teacher are the one who can develop proper relationships with students, she or he must be able to build students' confidence as well as ability to maintain discipline in the classroom deemed as the most important points. And to make their teaching activities more effective for learners, the teacher is also expected to know the need of the learners. In short, the teacher is also expected to be caring and responsible to their students.

In a study on psychological problems and challenge in EFL speaking classroom conducted by Win Listyaningrum (2017) from Gadjah Mada University, Indonesia, it was revealed that some psychological problems involved in speaking classroom were due to some factors such as: less-confidence, speech anxiety and low self-esteem. Students who have low of self-confidence level are hardly able to control themselves for public speaking in the classroom. He/she had difficulties in handling his or her own behaviour. Besides, they lose belief in themselves and thinking that his or her friends in the classroom miss-appraise them. Besides, they were also afraid of making mistakes in their presentation.

Some studies show that both teachers and students perceive speaking as an important language skill. In a research study, it was showed that $44.5 \%$ of teachers believe that speaking is very important and the students also rated speaking skills as important skills to master with $45.4 \%$. Both teachers and students perceive speaking skills as the most important skills compared to reading, listening and writing skills (Clarvie \& Fauziah, 2013). However, there are some challenges in teaching English speaking, especially when it comes to public speaking in English. One of the he main issues in English public speaking deals with effective ways to teach speaking in English including in teaching of public speaking.

Other techniques that can be used by teachers are to be generous with praise to the students, every time they have presentation. This will boost their confidence and 
subsequently make them love the subject. At the same time, a teacher also has to be patient with the students since they are different in terms of academic level as well as their proficiency and competency in English language. For the students, they have to practice public speaking tasks given by the instructors. It is advisable for students to practice public speaking task by using updated issues relevant to the lesson materials (Rahmah \& Puspita, 2012). It is advisable to use appropriate materials, especially from the local culture or materials or issues close to the learners (Chris Asanti, 2018).

Another way of teaching public speaking is through drama techniques. A study by Mine (2014) showed that drama could help reduce speaking anxiety in foreign language classes. It was found that drama application contributed significantly to the emotional quality of the English class. Students perceived that they felt much better and became eager to come to class. The drama medium could also help lower the speaking anxiety of the participants where the students started to speak English without the fear of making mistakes. In short, they enjoyed taking part in English speaking situation and setting.

In affective strategy, the students were asked to prepare a speech individually and also in a group. This strategy helps them forge cooperation where they work together using English in naturally relaxing situation. In social strategy, which is almost similar with affective strategy, the students were given task but in the form of composing paragraphs of speech text only. And lastly, they used other strategy using game activities. This strategy was to build up fun activity by providing game. This activity could provide chunks of the speech text and they subsequently discussed it together in the classroom before a complete speech text could be completed.

\section{Research Method}

This research is designed by using qualitative approach by using interview as instrument to solicit data from the respondents. Posted interview questions were sent via email. A set of interview questions depicting some questions on the process of teaching and learning English, especially on English public speaking component to students, was devised. For the sake of uniformity, the same set of questions were sent to all English teachers. Subjects for the interview are 11 English teachers who have had experiences in teaching English subject coded UBI 3012 at Universiti Sultan Zainal Abidin (UniSZA), one of the public universities in Malaysia. 


\section{Result and Discussion}

Analysis is based on the posted interview questions to 11 English language instructors at Universiti Sultan Zainal Abidin. All of the answers are presented in narrative way to get the essence of the interview content.

\subsection{Why is english public speaking important to students?}

There were 11 English teachers answered these questions. They had some differences as well as similarities in nature of their answers. Teacher 1 commented that English public speaking is the best and quickest way to see how fluent and competent a student is. She also opines that it also serves as a good medium for the students to express themselves verbally and physically. On the other hand, teacher 2 stresses on building confidence. He also added that besides building for confidence, public speaking also allows for real practice/usage of the language, ensures students to study and function in English before the public speaking event is conducted. In addition, Students will become better listeners and participate more in general discussions. Public speaking also teaches them how to be critical in their life (Gina, 2009).

In other word, public speaking skills actually can develop critical thinking among its speakers. With good skills of public speaking, someone can sharpen both their critical thinking and problem solving skills because when one delivers a speech in front of the public to a group of people or audience on any topic, the speakers will try articulating and conveying the message in such a way to make sure that everyone can understand it since the public speaking is more audience-centred (Osborn \& Osborn, 2003).

Teacher 4 and teacher 5 also share their similar views on the importance of building confidence as the outcome of the English public speaking. As a speaker continues getting involved in public speaking activities, she or he normally will become more fluent or seasoned thus making them a better speaker and it automatically will make them more confident. In contrast, teacher 3 sees other angle for the activity of public speaking. She seems to be more far-sighted by foreseeing the importance of mastering public speaking in the future workforce. She added that a successful public speaker will have a better chance in the future employment since they will be able to compete in job market as well as to go further in their future career. Someone who is good in public speaking will have some advantages during a job interview since he or she can maximize the interview skills that are very essential in the process of securing a good job. 
Teacher 7 expressed slightly different angle of thinking on this matter by mentioning that Public speaking helps her see how fluent and confident the students are in delivering their thoughts in English language. She firmly believes that English public speaking is important for students as it helps them to demonstrate their level of proficiency and at the same time give them an opportunity to share their thoughts confidently. Public speaking can also help the speakers grow their knowledge base. When someone prepares a speech or a talk, she or he has to be knowledgeable with the topic to be prepared. Unlike daily conversation, an oral presentation needs more detailed and complex preparation and it has to comply with some characteristics to meet its objectives (Choo, et.al, 2006).

Another opinion comes from teacher 8 who stressed out the importance of English public speaking as an avenue for the students to start using their critical thinking and at the same time they can start training how to control their anxiety to talk in front of audience. The same ideas were also shared by teachers 9 and 10 respectively. Public speaking is now very important for professionals especially when involving persuasion. Having the ability to persuade leads to convincing other people to undertake actions of the interest of the speaker.

\subsection{What do you expect students to get at the end of your english public speaking class?}

A discussion with regard to the expectations from students after taking English class, it is noted that most teachers hope that the students will have a much higher confidence level. With confidence, students are expected to have positive and realistic views of themselves and their situations. Self-confident people trust their own abilities, have a general sense of control in their live, and believe that, within reasons, they will be able to do what they wish, plan and expect (Eldred, et.al, 2004). Besides, students are also expected to have a broader scope of thinking and vision and can give opinion on some matters soundly. By having a sound confidence, coupled with the mastery of techniques of doing public speaking properly, the students should be able give ideas clearly in a very convincing way. They must be confident that they can do it.

Another concerned teacher also gives opinion that besides confidence and fluency talking in front of the public, a student also still needs to give attention to the rule of language, which is grammar. According to her, the mastery of good grammar will show the proficiency of someone in the language. This, according to her, will benefit the students in the long run. Another teacher gives a little bit moderate opinion by 
emphasizing that the public speaking class is expected to produce students who can express their ideas, even in simple way.

Another expectation of the instructors from the students upon completing their English speaking class is their ability to participate more in meaningful discussion, to share their knowledge with others, being an active listeners and participate more in discussions. According to De Vito (1998), one of the purpose of communication is to discover the external world by engaging in a communication via discussion. Besides, a discussion can be a good platform for the students to express their ideas clearly and communicate well with other people.

Next, through the English speaking class, the students are expected to overcome their anxiety in speaking in front of the public. At first, the students should focus on both fluency and accuracy of the language (Brown, 2007). The instructor plays a very important role to help reduce anxiety of the student when delivering their speech by giving motivation and giving lessons that can boost their confidence (Chitravellu, 2005). With proper practices, the students are expected to overcome their stage fright or nervousness so they can become very confident speakers.

\subsection{What are common weaknesses of your students in delivering their english public speaking?}

One of the most obvious weaknesses of the students during English public speaking is with regard to the eye contact. The students seem not to have good eye-contact during a public speaking where they do not look at the audience. Instead, they simply just read as if there are no audience in front of them. A poor eye-contact shows that a speaker is not confident with his presentation and from the audience side, it is not considered respectful. At the same time, eye contact also functions to maintain the attention of the audience. The failure to maintain the audience's attention will result in the speech gone unheeded and unheard. A poor eye contact also reflects less confidence and low selfesteem from the speaker (Win Listyaningrum, 2017; McDonald, 2001; Hysook \& Adam, 2006; Phillips, 1992; Gholam, et. al, 2013). The problems of poor eye contact, lack of confidence and low self-esteem during an English public speaking presentation were also expressed by most of 321 students in the study when they presented individually.

Other common weaknesses are their poor mastery of grammar and their limited vocabulary in the English language (Mine, 2014; Bandar \& Abdul, 2017). If they do not have much knowledge on grammar and vocabulary, they will find it difficult to speak since they cannot express their mind properly due to the limitation of words 
and the structures of the language. For example, if they are in the middle of public speaking presentation, they run out of ideas and do not know what to say, it will give bad impression to the speakers. The problems of lack of grammar and lack of vocabularies were also expressed by majority of undergraduate students of Universiti Sultan Zainal Abidin when they delivered their English public speaking based on their opinion when individual presentation was conducted to 321 respondents.

Another weakness of the students' presentation in English public speaking is that, most of the students are afraid of making mistakes (Ahmed, 2016; Win Listyaningrum, 2017). The students are so highly conscious that the mistakes made during a public speaking presentation is considered as failures. For a public speaking presentation, there is a balance between both fluency and accuracy (Brown, 2007) where the students should not be worried too much if they make mistakes, provided the message is delivered fluently.

Some students also have a high level of shyness during a public speaking that impedes their presentation (Ahmed, 2016; Jafar, Noorizah \& Rosniah, 2016). The shyness should be avoided if someone wants to speak and express their ideas freely and confidently in front of the audience. Being shy in front of the public will only give bad impression. Besides, the prepared speech cannot be fully conveyed if the speaker is not free to express themselves. It also goes to nervousness to the speaker that can impede the good flow of the presentation. If someone is nervous, he or she can have shaky hands, dry mouth, blank mind, shortness of breath, trembling legs, etc. (Coopman \& Lull, 2012) that will completely disturb the presentation.

Lastly, poor delivery, monotonous presentation, bad voice projection also contributes in the poor presentation. A speaker has to be energetic, enthusiastic and cannot be monotonous in front of the public. Likewise, bad voice projection will give bad effects towards the presentation since the audience cannot clearly listen to what the speaker says and delivers. Poor body language can also cause a presentation dull and not interesting since the speaker stands still without making proper movements in tandem with the presentation made.

\subsection{What do you think are the causes of your students' weak- nesses in delivering their english public speaking?}

The first cause of the weaknesses is due to shyness ( Jafar, Noorizah \& Rosniah, 2016; Ahmed, 2016). The shyness experienced by the speaker will result in a presentation not fluently or smoothly done. Secondly, the notion that many students do not like the 
English language due to some reasons. One of them maybe due to their background, or lack of exposure to the language as well as due to the teaching of the subject that doesn't interest the learners. Third, the culture of not reading among the students has caused them not to have enough vocabulary to use in delivering their English public speaking. Besides, many students use English language but they still think and perceived their mind using their mother-tongue or their first language. This will impede the process of good flow in the composition and delivery of a good speech in English.

The next reasons are due to limited possession of vocabulary and limited mastery of the English grammar (Mine, 2014; Bandar \& Abdul, 2017). If a speaker does not have good knowledge of grammar and at the same time have only limited vocabulary, he or she will have hard time to have good delivery of a public speaking in English. Next, lack of motivation in learning English and improving the public speaking skills also contributed to the deterioration of the English public speaking skills (Nguyen \& Tran, 2015; Bandar \& Abdul, 2017). A motivated speaker will put their full effort and resources to ensure that the speech is perfectly delivered with confidence.

Low self-confidence level and low self-esteem play a crucial role in ensuring a success of a public speaking. If someone has low-self-confidence and low self-esteem they cannot execute and deliver a speech well (McDonald, 2001; Gholam, et.al, 2013). Meanwhile, a speaker with a lack of ideas in their mind will not be able to give a good presentation since they do not have ideas to deliver to the audience. And the last cause of the weakness in the English public speaking is lack of preparation or practice from the speaker since the English language is not given due emphasis or priority by the speaker.

\subsection{Can you give comments on their english linguistic competence (the use of english language grammar) when delivering their english public speaking?}

Although grammar is not the only factor that plays in the delivery of a public speaking, the mastery of a sound English grammar will give some added value to the speaker. From the observation of the English teachers, most of the students still lack of good grasp of English grammar. For example, they still struggle to fully understand the basic tenet of grammar in the form of tenses or parts of speech. The other most commonly made mistakes is in the use of subject-verb agreement in a sentence. Mostly they are trapped with errors but continue speaking although with a broken grammar (Richards, 1971; Dulay, et.al, 1982). 
Another issue in the use of language during public speaking is the influence of their mother-tongue, especially in Malay language. Even in one of the interview conducted to the students, they admit that English is not their mother tongue. They do speak Malay language daily, even speak in their dialect. This factor helps impede the fluency of the students to speak in English, let alone, to speak in front of the public. But if they want, they need some practice, practice and more practice to use the language to make them get used to using the language.

Other English grammar that the students need to improve are with respect to the tenses, parts of speech, formation of sentences and improvement of their vocabulary. A wrong tense used in the sentence will result a sentence to be ungrammatical that can change the meaning. A wrong word used in a sentence can also lead to confusion to the listeners. In order to make a speaker good at using the English grammar, he or she has to expose themselves by writing, reading and subsequently making presentation to build confidence with their linguistic competence in English language. The same types of errors in the English spoken language were also found in previous studies conducted by Nesreen (2014) and Akhadiyatus (2017).

Other obvious errors in the English spoken language made were on the use of subject-verb-agreement (Rula \& Islam, 2013). Some examples are: I am afraid, my grammar are wrong (Correction: I am afraid, my grammar is wrong), My face become red and I have dirty palms (Correction: My face becomes red and I have dirty palms). The errors in the use of subject-verb-agreement were made by most of the students from each faculty at the UniSZA who were involved in the study.

\subsection{Did you see and observe any sign of anxiety or fear of speaking among your students in delivering their english public speak- ing? (If Any): What do you think caused those anxiety or fear?}

The feeling of anxious or anxiety or sometimes called stage -fright is very common in speaking in public (McCroskey, 1982). According to the teachers, they observe a sign of anxiety, even before a student makes a presentation. The feeling of nervous or anxious has captured their mind thus making them more difficult to focus and deliver their speech. But according to the teachers, if a student is prepared with their preparation, normally the student can deliver a speech. So, in this case, preparation is not enough. This finally haunts them to present and do not know what to present. Lack of preparation was also cited by undergraduate students of UniSZA as one of their problems in the English public speaking that was disseminated during their individual presentation. 
However, one teacher opined that, actually the feeling of anxious or anxiety is not obvious during presentation. What is obvious there is the intention of the student to finish her presentation as soon as possible. This action can cause them lose some good ideas and the delivery of presentation cannot be done perfectly as planned. They seem not so confident and look nervous in front of the public.

Again, the elements of nervousness and stage-fright occur since the students do not have high level of self-confident. If the students have low self-confident (McDonald, 2001; Hysook \& Adam,2006) and low self-esteem (Phillips, 1992; Gholam, et.al, 2013) the speakers will not be able to deliver their speech well as planned. Besides, the speakers also lack of practice and preparation (Mine, 2014; Jafar, et.al, 2016) that cause their presentation a failure or imperfect. This problem will be worsened with the poor grasp and mastery of grammar and limited vocabulary by the speaker that leads to a presentation that is not properly organized. These matters were also revealed in past studies conducted by Win Listyaningrum (2017) and Bandar and Abdul (2017).

\subsection{What would you recommend your students do in order to improve their english public speaking skills (In terms of com- petence and performance)?}

Indeed, there are some good recommendations given by the English teachers in the efforts to improve their English public speaking skills and performance. The first one is to advise students not to be scared of English language. They are encouraged to speak more and to use more the language. By using the language daily basis, they will have more confidence to use it. Another teacher recommended students to think in English in order to speak better. Thinking in English actually means that the students should master many vocabularies in order to make them stay in the discussion or presentation. Lack of vocabulary usually will impede students from speaking more.

There is also another piece of advice form a teacher where she does not give focus on the mastery of grammar so much since what she thinks more important in public speaking is the fluency during the presentation. She doesn't want the students to be tightly bound by the boundary of grammar world till they are overly scared to open their mouth fearing of making mistakes in grammar. Besides, she advised to use a better body language during a presentation. And finally, ample practices will be the best thing to do since a speaker is not born but trained, day by day, month by month before someone is deemed as a seasoned speaker. 
Reading is another way of helping the speakers build their confidence when doing the English public speaking. By having enough vocabulary in their storage it will make the process of public speaking more smoothly done since the speakers are always ready with ample vocabularies to be delivered during the English public speaking. Besides, the more the speakers read, the more vocabularies she or he has and at the same time, he or she can pick up knowledge of grammar indirectly due to intensive reading of the language.

\subsection{Could you share your best teaching method that you think can help students to improve their english public speaking skills?}

There are some good techniques used by the English teacher in teaching English language in the class, including teaching of public speaking. One of the popular techniques is by using story telling. This activity looks simple, but it actually carries a lot of messages and needs a sound skill to execute it. Not everyone can be a good story teller. Story telling will train someone with controlling the language, the use of emotion and a lot of body movement to make a story livelier.

Some teachers also like to use technology in teaching, such as the use of audio recording or video showing to arrest the attention of the students. Besides, these materials now are easy to find and they are very interesting and up to date. Many young learners now prefer the use of technology in class rather than the old way of talk and chalk. It is found now that the students prefer using YouTube in the learning process (Stella, K \& Dimitris, 2013). This idea has been mentioned by Watkinsand (2011) in his research by inserting that YouTube is a valuable tool that can improve multiple foreign language skills.

Another popular method used now is with presentation matrix. This technique helps students outline their ideas for a presentation from start to finish. The outline works for short or long presentations, and can easily be remembered and followed. The use of this presentation matrix is fully controlled and monitored by the instructor as to ensure the objectives of the lessons can be achieved (Chitravellu, 2005).

Other practical way in teaching English public speaking is to use the instructor as the role model for the students to emulate. In this case, the instructor should show a good model to students to follow in terms of pronunciation, stress, range of vocabulary, body language, facial expressions, structures, etc. (Chitravellu, 2005). If that is the technique used, it is to ensure that the instructors should have some characteristics. 
Firstly, the instructor must be proficient in English. Secondly, he must know pedagogical knowledge, organizing the class and has good communication and socio-affective skills.

Other techniques commonly used are role play and language games (Muamaroh, 2017). This technique will allow the students to be creative and use their creativity to think and execute the games in English using their skills in English grammar and spoken language as well. In role play, a speaker is trained to emulate someone or a certain character, from the pronunciation, structures of words, body language, etc. Meanwhile language games teach the students some fun games related to English language where the learners can use inferential learning where they use the English language while learning the language without being realised.

Other techniques are also popular such as experience sharing in the class where every single student will share their stories in English and others will ask questions accordingly. But the best way to make students confident in their presentation is by allowing the students to come up with their own topic to choose. By having their own topic, it will make them much easier to develop the topic thus resulting in making a good speech where all the contents come from the students. The role of teacher or instructor here is just to monitor and guide if the students need help (Chitravellu, 2005).

\section{Conclusion}

The English teachers at Universiti Sultan Zainal Abidin have given their constructive comments and remarks on the students' performances, attitudes as well as suggestions on how to improve the English public speaking.

The English language instructors are of the opinion that English public speaking is important to students because it can build confidence for the students and at the same time, the students can express their ideas clearly and critically. Besides, the English public speaking can give them an edge in the workforce in the future where the English public speaking can nurture their communication skills and fluency in speaking which are crucially important in the job market.

The English instructors also expect the students to gain something at the end of their English public speaking class such as the confidence to speak in front of the public, manage to attract audience interest in speaking, manage to involve in discussions, use English in daily life and most importantly is to overcome anxiety during a public speaking delivery in order to communicate well with the audience in terms of expressing their ideas. 
Some weaknesses of the students are identified by the English instructors when the students deliver their English public speaking, such as: poor eye contact, cannot maintain the attention of the audience, poor voice projection, cannot organise ideas properly, lack of grammar knowledge, limited vocabulary, lack of confidence, poor body language, too shy, afraid of making mistakes, nervous, monotonous, and poor delivery in general.

When it comes to discussion on the causes of the students' weaknesses in delivering their English public speaking, the instructors cited some factors such as: shyness, students dislike English and English is not their priority, lack of reading thus limiting their vocabulary, not functioning in English, lack of motivation, lack of grammar and vocabulary, lack of practice, low self-confidence, low self-esteem and lack of ideas.

Commenting on the students' linguistic competence in the use of English language grammar when delivering their English public speaking, the English instructors gave their comments as follows: There is a great influence from the first language (L1) of the student, the grammar is rather broken, lack of vocabulary, making a lot of incomplete sentences, very weak in using subject-verb-agreement, the use of wrong tenses, the use of wrong parts of speech. There are also problems with pronunciation among the students.

Commenting on their observation of the students with respect to stage fright or anxiety when the students deliver their English public speaking, the English instructors gave varied answers. A few instructors think that the fear or stage fright is not that obvious. But mostly, the instructors opine that most students experience nervousness, anxiety, stage fright during presentation. It also shows the students have low selfconfidence level.

The instructors also recommend some ways to the students to improve their English public speaking with the following suggestions: not to be scared of English language, to speak more actively in English, to read more English reading materials, to think in English language, when speaking not to focus on grammar but fluency, improving body language when delivering a speech and most importantly is to motivate themselves in improving their English by practising more and more.

On the ideas of the best teaching methods in teaching English public speaking to undergraduate students at UniSZA, the instructors give some techniques as follows: to share their own experiences as topics, storytelling, using presentation matrix, making an instructor as a good role model in speaking, making guided outline speech, allowing students to present their own topics of their choice, showing videos on public speaking, language games, role-plays and impromptu speech. 
As general conclusion, the English teachers at Universiti Sultan Zainal Abidin have given their constructive comments and remarks on the students' performances, attitudes as well as giving suggestions on how to improve the English public speaking. The main reasons for the poor public speaking presentation are due to nervousness, lack of preparation, lack of vocabulary has caused this problem. Some suggestions have been forwarded by the English teachers for the students. These findings support the theory of communicative competence that was coined by Dell Hymes $(1972,1967)$ that was cited in Brown (2007).

\section{References}

[1] Ahmed Maher, M.A.N. (2016). Problems and Difficulties of Speaking that Encounter English Language Students at Al-Quds Open University. International Journal of Humanities and Social Science Invention, 5 (12), 96-101.

[2] Akhadiyatus, S. (2017). Errors on Speech Production Made by The First and Thirds Semester Students of English Education Department of UII in Speaking Class for Academic Year 2016/2017. (Unpublished Master's Thesis). Universitas Muhammadiyah Surakarta, Indonesia.

[3] Asanti, C., \& Syamdianita. (2018). Local and Target Culture Materials: Insight into Teachers' Perspectives. Proceedings of the 1st Annual International Conference on Language and Literature (AICLL), UISU, Medan, Indonesia. doi: 10.30743/aicll.v1i1.33

[4] Bandar, M.S., \& Abdul, S.P. (2017). Teaching English Speaking Skills to the Arab Students in the Saudi School in Kuala Lumpur: Problems and Solutions. International Journal of Education \& Literacy Studies, 6 (1), 1-11.

[5] Brown, H.D. (2007). Teaching by Principles. New York: Longman.

[6] Chitravelu, N., Sithamparam, S., Choon, TS. (2005). ELT Methodology: Principles and Practice. Selangor: Fajar Bakti Sdn. Bhd.

[7] Choo, W.Y, et.al. (2006). Oral Presentation Skills. Local Publication: Selangor, Malaysia.

[8] Clarvie, M.C., \& Fauziah, H. (2013). I doesn't know English: Beliefs and Practices in teh Teaching of Speaking in ESL Classroom. Pertanika J. Soc Science \& Humanities, 21 (2), 449-460.

[9] Coopman, S.J., \& Lull, J. (2012). Public Speaking: The Evolving Art. Stamford: Wadsworth.

[10] Dulay, et.al. (1982). Language Two. New York: Oxford University Press. 
[11] Eldred, J., Ward, J. \& Dutton, Y. (2004). Catching Confidence. Leicester: National Institute of Adult Continuing Education.

[12] Gholam, A.K. Et.al. (2013). the influence of EFL students' self-esteem on their speaking skills. The International Journal of Language Learning and Applied Linguistics World, 2 (2), 76-83.

[13] Gina, I.S. (2009). Using Public Speaking Tasks in English Language Teaching. English Teaching Forum, 47 (2), 18-23.

[14] Hidayah, Ahmad Taufik (2007). Error Analysis on The Use of The Simple Present Tense and The Simple Past Tense in Writing Essays Among Tes/ College Students: A Case Study. (Unpublished Master's thesis). Universiti Pendidikan Sultan Idris, Malaysia.

[15] Hyesook, P., \& Adam, R.L. (2006). L2 Learner's Anxiety, Self-Confidence and Oral Performance. Retrieved on 23 June 2018 from http: www.semanticscholar.or/paper

[16] Jaafar, M.B, Noorizah, M.N., \& Rosniah, M. (2016). Speaking Anxiety among English as a Foreign Language Learner in Jordan: Quantitative Research. International Journal of Education and Research, 4, 63-82.

[17] McCroskey, J.C. (1982). An Introduction to Rhetorical Communication. Englewood Cliffs, N.J: Prentice-Hall.

[18] McDonald, A. (2001). The prevalence and effects of test anxiety in school children. Educational Psychology, 21 (2), 89-101.

[19] Mine, A. (2014). The reduction of speaking anxiety in EFL learners through drama techniques. Social and Behavioral Sciences, 176, 961-969.

[20] Muamaroh. (2017). Students' Perception on Teaching Techniques Applied by English Teacher in the speaking Class. Proceedings of the 5th URECOL. 2017, at UAD. Yogyakarta.

[21] Nesreen, S.A. (2014). Errors Analysis: A Case Study of Saudi Learner's English Grammatical Speaking Errors. Arab World English Journal, 5 (4), 84-98.

[22] Nguyen, H.T., \& tran, N.M. (2015). Factors Affecting Students' Speaking Performance at Le Thani Hien High School. Asian Journal of Educational Research, 3 (2), 8-22.

[23] Osborn, M and Osborn, S. (2003). Public Speaking. New York: Houghton Mifflin Company.

[24] Phillips, E. (1992). The effects of language anxiety on students' oral test performance and attitudes. Modern Language Journal, 76, 14-26.

[25] Rahmah., \& Puspita, S. (2012). Improving Students' Speaking Achievement through Public Speaking Tasks. Transform Journal of English Language Teaching and Learning of BS Untimed, 1 (1), 1-8. 
[26] Richards, J.C. (1971). A non-contrastive approach to Error Analysis. English Language Teaching Journal, 25, 204-209.

[27] Roya, Z., \& Saideh, A. (2016). Characteristics of an Effective English Language Teacher (EELT) as Perceived by Learners of English. International Journal of Foreign Language Teaching \& Research, 4 (14), 69-83.

[28] Rula, T.T., \& Islam, M.A. (2013). The Spoken Errors and Mistakes Committed by Senior English Students at Princess Alia University College. Theory and Practice in Language Studies, 3 (3), 497-502.

[29] Stella, K., \& Dimitris, E. (2013). Students' Perceptions of Effective EFL Teachers in University Settings in Cyprus. English Language Teaching, 6 (11), 1-16.

[30] Watkinsand, J., \& Wilkins, M. (2011). Using YouTube in the EFL Classroom. Language Education in Asia, 2 (1), 113-119.

[31] Win, L.A. (2017). Psychological Problems and Challenge in EFL Speaking Classroom. Language \& Language Teaching Journals, 10 (1), 29-47. 